\section{AUTHORS:}

Wonroo B.A. Bancole ${ }^{1}$

Mark D. Laing ${ }^{1}$ (iD

Kwasi S. Yobo ${ }^{1}$ id

Abou Togola ${ }^{2}$

\section{AFFILIATIONS:}

'Discipline of Plant Pathology, School of Agricultural, Earth and Environmental Sciences, College of Agriculture, Engineering and Science, University of KwaZulu-Natal, Pietermaritzburg, South Africa 2International Institute of Tropical Agriculture (IITA), Kano Station, Kano, Nigeria

CORRESPONDENCE TO: Kwasi Yobo

EMAIL:

Yobok@ukzn.ac.za

\section{DATES:}

Received: 31 Jan. 2020

Revised: 17 Apr. 2020

Accepted: 21 Apr. 2020

Published: 26 Nov. 2020

\section{HOW TO CITE:}

Bancole WBA, Laing MD, Yobo KS, Togola A. Establishment of Beauveria bassiana isolates as endophytes in rice cultivars and their biocontrol efficacy against rice stem borer, Sesamia calamistis. S Afr J Sci. 2020;116(11/12), Art. \#7914 9 pages. https://doi.org/10.17159/ sajs.2020/7914

\section{ARTICLE INCLUDES:}

囚 Peer review

$\square$ Supplementary material

\section{DATA AVAILABILITY:}

$\square$ Open data set

冈 All data included

$\square$ On request from author(s)

$\square$ Not available

$\square$ Not applicable

EDITORS:

Teresa Coutinho iD

Salmina Mokgehle (iD)

KEYWORDS:

entomopathogenic fungi, cereal grain, colonisation, inoculation

\section{FUNDING:}

Organization for Women in Science for the Developing World (OWSD), Plant Health Products (KwaZuluNatal, South Africa)

\title{
Establishment of Beauveria bassiana isolates as endophytes in rice cultivars and their biocontrol efficacy against rice stem borer, Sesamia calamistis
}

\begin{abstract}
Possible endophytic colonisation of rice cultivar parts (leaves, stem and roots) by Beauveria bassiana isolates and their potential as biocontrol agents against Sesamia calamistis Hampson (African pink stem borer) were investigated. Five promising $B$. bassiana isolates were evaluated for their endophytic colonisation, the effectiveness of the inoculation methods and the efficacy of the isolates as biocontrol agents against $S$. calamistis The plant part colonised is often dependent on the inoculation method. Colonisation of plant parts was assessed at 30 and 60 days after seed inoculation and foliar spray. For the pathogenicity activity, third instar larvae of $S$. calamistis were fed with rice stems that were previously inoculated with endophytic isolates of $B$. bassiana. Both inoculation methods led to the colonisation of the rice cultivar tissues, but were affected by the interactions of cultivars $x$ isolates $x$ inoculation methods. The colonisation of the cultivar plant parts varied over time (30- and 60-day intervals), and was affected by the inoculation method used. For both inoculation methods, highly significant differences were observed in the roots and the leaves over time $(p=0.0001)$. However, with seed treatment, there was no significant difference in levels of colonisation in stems by the isolates $\mathrm{x}$ time $(p=0.32)$ The $B$. bassiana isolates were pathogenic on the third instar larvae of $S$. calamistis, causing mortalities of more than $50 \%$ at 28 days after treatment. However, the virulence of the isolates varied. According to the isolates and the inoculation methods, $B$. bassiana formed an endophytic relationship with rice plants, and produced various mortality rates.
\end{abstract}

\section{Significance:}

- $\quad$ Beauveria bassiana could be a potential biocontrol agent of rice stem borer, $S$. calamistis as there is no report of endophytic isolates of $B$. bassiana for the control of rice borers.

- $\quad$ Currently there is no commercially registered biocontrol agent against rice borers; hence further studies into $B$. bassiana could lead to the registration and commercialisation of $B$. bassiana as a bio-pesticide for rice stem borers.

\section{Introduction}

Rice (Oryza spp L.) is one of the world's most important crops, providing food for more than half of the world's population. ${ }^{1-3}$ Rice and wheat (Triticum spp L.) together contribute about $21 \%$ of the total energy consumed by humans. ${ }^{4}$ In West Africa it has become the main source of calories for low-income households. ${ }^{5}$ Two Oryza spp. are cultivated globally: Asian rice (Oryza sativa L.) and African rice (Oryza glaberrima S.), for which the cultivation is limited to tropical West Africa. ${ }^{6}$ Rice is now grown and consumed in more than 40 countries on the African continent. ${ }^{7}$ Its consumption has increased rapidly in Africa, making it the second largest source of carbohydrates in sub-Saharan Africa. ${ }^{4}$ Imports of rice account for nearly $40 \%$ of the total rice consumption of the region. ${ }^{8,9}$

Losses caused by biotic factors such as pests, diseases and weeds reduce yields of rice worldwide. According to estimates of the Food and Agriculture Organization of the United Nations (FAO), diseases, insects and weeds cause as much as $25 \%$ yield losses annually in cereal crops. ${ }^{2}$ The most serious pests of rice plants worldwide are rice stem borers, which belong to three families (Noctuidae, Pyralidae and Diopsidae). Sesamia calamistis Hampson (Lepidoptera: Noctuidae) is one of the major pests that attacks grain crops including rice, maize (Zea mays L.), pearl millet (Pennisetum sp L.), wheat, sorghum (Sorghum bicolor L.) and sugarcane (Saccharum officinarum L.). The control of this borer by commercial farmers has mainly relied on the application of synthetic insecticides. ${ }^{10-12}$ However, control of $S$. calamistis using chemicals is difficult because of a prolonged emergence pattern, multiple generations and a cryptic feeding behaviour. ${ }^{13} \mathrm{~A}$ further issue is that, as with many other stem borers, $S$. calamistis has developed resistance to chemicals. In addition to the insecticides' high costs and their inefficacy against the borers, they may also cause ecological problems, and are usually unaffordable for small-scale farmers. ${ }^{14-17}$

The need for alternative methods for the control of major pests has driven research to develop biological control products. Indigenous predators, parasites and entomopathogens are the most commonly used biological control agents in tropical Asia and Africa to control stem borers. ${ }^{18}$ Entomopathogenic fungi are important among biological control agents due to their broad host range, their diverse mechanisms of pathogenicity, and their environmental safeness. ${ }^{19-21}$ Some strains of the entomopathogen $B$. bassiana have been introduced into several plant species [maize, banana (Musa spp L.), tomatoes (Solanum lycopersicum L.), sorghum, coffee (Coffea arabica L.), wheat and pumpkins (Cucurbita spp D.)] to control various insects. ${ }^{22-25}$ Various inoculation methods (seed treatments, soil drenches, foliar and flower sprays, and stem injections) have been used for their establishment as endophytes in those crops. The main reason for conducting this study was to determine if endophytic strains of $B$. bassiana in rice cultivars might provide protection against $S$. calamistis, the major rice stem borer prevalent in West Africa. 


\section{Materials and methods}

Five isolates of $B$. bassiana previously identified as endophytes in sorghum were evaluated for their potential establishment as endophytes in rice cultivars plant tissues. Third larval instars of $S$. calamistis were used as the test insects.

\section{Production of conidial suspensions of B. bassiana isolates}

Five $B$. bassiana isolates $(\mathrm{Bb} 3, \mathrm{Bb} 4, \mathrm{Bb} 10, \mathrm{Bb} 21$ and $\mathrm{Bb} 35)$ were used for the study. These had been isolated from various soils, including soil samples collected from the rhizosphere of mangoes (Mangifera indica L.), rooibos tea (Aspalathus linearis Burm. f.) and wheat. They were characterised by the Plant Protection Research Institute (Pretoria, South Africa). In prior research, they were selected for their endophytic abilities in sorghum plant tissues (leave, stem and root). ${ }^{18}$ Conidial suspensions used for the study were prepared following the method of Parsa et al. ${ }^{18}$ The strains were cultured in $90-\mathrm{mm}$ diameter plastic Petri dishes containing potato dextrose agar (PDA) supplemented with antibiotics (100 mg/L of ampicillin and streptomycin), and incubated at $28{ }^{\circ} \mathrm{C}$. The cultures were allowed to grow for 14-18 days, after which the conidia were harvested. The conidia were harvested under sterile conditions by gently scraping the fungal growth from the surface of the agar with a sterile spatula, and rinsing with sterile distilled water. The resulting suspensions were filtered using sterile cheese cloth to remove mycelia and agar debris. Conidial density was determined using an improved Neubauer haemocytometer, and adjusted to $2 \times 10^{6}$ conidia/ $\mathrm{mL}$ with sterile distilled water containing Tween-80 $(1 \mathrm{~mL} / \mathrm{L})$. The viability of the conidia for all the experiments was evaluated by taking a $100-\mu \mathrm{L}$ sample of each strain, spreading it on PDA and incubating at $25^{\circ} \mathrm{C}$. Conidia germination was assessed after $24 \mathrm{~h}$ of incubation. The percentage germination of conidia was determined from 100 randomly selected conidia under a light microscope. The germination of conidia was assumed when the hyphae were visible or the germ tube was about twice the length of the conidium. For each strain, the mean of three replicates was used to assess the viability of the conidia. The final inoculum was used for seed treatment and foliar spray experiments.

\section{Production of rice plants for greenhouse studies}

Three African rice cultivars (NERICA1, NERICA8 and NERICA-L19)26 were used as the host plants as there may be differential interactions between host plants and endophytic strains. Seeds of each cultivar were separately surface sterilised in $3 \%$ sodium hypochlorite for 3 min followed by $70 \%$ ethanol for 2 min. They were rinsed three times with sterile distilled water, air dried on a laminar flow bench and then divided into two sets. The first set was used for seed inoculation and the second for foliar spray experiments. The second set of seeds used for foliar spray experiment were sown in Speedling ${ }^{\circledR} 24$ trays filled with Composted Pine Bark (CPB) seedling mix growing medium. The seeds were watered with tap water and placed under greenhouse conditions at $20-28^{\circ} \mathrm{C}$ day and night. Two weeks after germination, the seedlings were transplanted into $30-\mathrm{cm}$ diameter pots filled with CPB seedling mix growing medium and placed under greenhouse conditions at $20-28{ }^{\circ} \mathrm{C}$ day and night. The plants were allowed to grow for 7 days before being used in the foliar spray experiment. Plants were irrigated three times a day with irrigation water containing NPK fertiliser [3: 1: 3 (38)] (50\%) together with calcium nitrate (50\%) and trace elements.

\section{Inoculation of B. bassiana isolates for endophytic colonisation in rice cultivars}

\section{Seed treatment}

The seeds of the three rice cultivars were surface sterilised as previously described. After surface sterilisation, the seeds for each cultivar were separately soaked in the conidial suspension of each $B$. bassiana isolate [ $5 \mathrm{~mL}$ of the prepared inoculum $\left(2 \times 10^{6} \mathrm{conidia} / \mathrm{mL}\right)$ ], allowed to stand overnight, then removed and air dried on a laminar flow bench. The seeds were then planted in Speedling ${ }^{\circledR} 24$ trays filled with CPB seedling mix growing medium. The control plants consisted of non-inoculated seeds treated in a similar manner using sterile distilled water. After
2 weeks, the emerging seedlings were transplanted into $30-\mathrm{cm}$ diameter pots filled with CPB seedling mix growing medium and placed under greenhouse conditions at $20-28^{\circ} \mathrm{C}$ day and night. Three plants per pot were arranged in the greenhouse in a randomised complete block (RCB) design with three replicates. Plants were irrigated three times a day with irrigation water containing NPK fertiliser [3: 1: $3(38)](50 \%)$ together with calcium nitrate $(50 \%)$ and trace elements. The plants were grown for 30 or 60 days before they were harvested, and the roots, stems and leaves were evaluated for evidence of endophytic colonisation.

\section{Foliar spray}

The seedlings of the three rice cultivars were sprayed 15 days after transplanting into pots. A hand spray was used to inoculate the rice plant leaves with the inocula of the $B$. bassiana isolates. A volume of $50 \mathrm{~mL}$ inoculum of each $B$. bassiana isolate was used per plant. Before the leaves were sprayed, the base of each pot was covered with aluminum foil, with a hole to allow the plant to emerge. This was to stop inoculum running off the leaves onto the roots and creating a root drenching situation. Plastic bags were used to cover the entire plant for $24 \mathrm{~h}$ to increase humidity. For the control plants, sterile distilled water was applied in a similar manner as described for the $B$. bassiana treatments. The treated plants (three plants per pot) were then placed in a greenhouse $\left(20-28{ }^{\circ} \mathrm{C}\right.$ day and night) using a RCB design with three replicates. Plants were irrigated three times a day with irrigation water containing NPK fertiliser [3: 1: 3 (38)] (50\%) together with calcium nitrate $(50 \%)$ and trace elements. The roots, stems and leaves of each treated plant were harvested after 30 and 60 days, for evaluation for endophytic colonisation.

\section{Evaluation of endophytic colonisation of the B. bassiana isolates}

The colonisation of rice plant tissues by $B$. bassiana was determined 30 and 60 days after inoculation with each $B$. bassiana isolate. From each rice cultivar $\times B$. bassiana treatment combination, plants were carefully removed from their pots and sampled into leaves, stems and roots. The roots were gently washed with tap water to remove residues of CPB. The plant tissues were surface sterilised by immersing them in $3 \%$ sodium hypochlorite for $3 \mathrm{~min}$, followed by $70 \%$ ethanol for $2 \mathrm{~min}$. They were rinsed three times with sterile distilled water. The surface sterilised samples were placed on sterile tissue paper under a laminar flow cabinet for air drying. After drying, six pieces of each of the samples (leaves, stem and roots) from each treated plant were randomly taken and plated separately onto a $B$. bassiana selective medium ( $39 \mathrm{~g} / \mathrm{L} \mathrm{PDA}$ $+2 \mathrm{~g}$ yeast extract $+1.1 \mathrm{~g}$ Dodine $+100 \mathrm{mg} / \mathrm{L}$ of streptomycin and ampicillin $)^{27}$ and incubated for 15 days at $25^{\circ} \mathrm{C}$. To confirm that the surface sterilisation was effective, $10 \mathrm{~mL}$ of the sterile distilled water used to rinse the samples during the surface-sterilisation procedure was spread onto Petri dishes containing the $B$. bassiana selective media. The plates were incubated for $10-15$ days at $25^{\circ} \mathrm{C}$ to count the colony forming units. However, the sterilisation resulted in clean plates Therefore, any $B$. bassiana mycelium emerging from surface-sterilised plant tissues was assumed to have originated from within the plant tissues as an endophyte. The plates that contained the plant samples were monitored every 2-3 days for the emergence of fungal mycelia. After $10-15$ days, the presence or absence of $B$. bassiana colonies were recorded. The fungal colonies grown from the samples were confirmed to be $B$. bassiana based on morphological characteristics.

\section{Mass rearing of S. calamistis larvae}

A suitable number of $S$. calamistis pupae collected from a maize field were placed into cages that contained cotton soaked in sugar/honey water that served as food for the moths once they emerged from the pupae. Sheets of transparent paper were wound around wooden rods $(40 \mathrm{~cm})$ to create a slot for the female moths to lay their eggs. These eggs were harvested from the slots by scraping the wooden rods with a sterile spatula. The eggs were placed into plastic containers on a sterile paper towel. The containers were incubated at $26^{\circ} \mathrm{C}$ with a relative humidity of $60 \%( \pm 10 \%)$, and a photoperiod of 12-h light and 12-h dark. The containers were monitored daily until the larvae 
hatched, creating the stage called 'black heads' (first instars). These young larvae were transferred into other transparent plastic containers whose lids were perforated but covered with mosquito netting to ensure permanent ventilation, and were incubated at $26^{\circ} \mathrm{C}$. Fresh maize stalks were harvested and placed into the plastic containers to serve as food for the black head larvae. After 3 days, the maize stalks were dissected and the larvae were extracted and transferred into new containers that contained fresh maize stalks (Figure 1), and kept in an incubator at $26^{\circ} \mathrm{C}$. This procedure was repeated until larvae of the desired third instar larval stage had developed. The number of days for each stage varied from one larval stage to the next. Development from the second to the third instar took 5 days, while development from the third to the fourth instar took 8-10 days.

\section{Production of endophytic stems of rice plants}

Seeds of a rice cultivar (NERICA 1) were surface sterilised in $3 \%$ sodium hypochlorite for $3 \mathrm{~min}$, followed by $70 \%$ ethanol for $2 \mathrm{~min}$. They were then rinsed three times with sterile distilled water and air dried. The surfacesterilised seeds were then dipped separately in a conidial suspension of each of the five $B$. bassiana isolates [5 $\mathrm{mL}$ of the prepared inocula $\left.\left(2 \times 10^{6} \mathrm{conidia} / \mathrm{mL}\right)\right]$ and left overnight before air drying under a laminar flow cabinet. The seeds were then planted in Speedling ${ }^{\circledR} 24$ trays filled with CPB seedling mix growing medium. After 2 weeks, the seedlings were transplanted into $30-\mathrm{cm}$ diameter pots filled with CPB seedling mix growing medium and placed under controlled greenhouse conditions set at $20-28{ }^{\circ} \mathrm{C}$ day and night. Three plants per pot were arranged in the greenhouse in three replicates per treatment, using a RCB design. Plants were irrigated three times a day with irrigation water containing NPK fertiliser [3: 1: $3(38)](50 \%)$ together with calcium nitrate (50\%) and trace elements. The plants were allowed to grow for 30 days before one plant per treatment from each crop cultivar was harvested and sampled (stems) to confirm their endophytic colonisation by $B$. bassiana isolates. The stems were separately surface sterilised by immersing them in $3 \%$ sodium hypochlorite for $3 \mathrm{~min}$, followed by $70 \%$ ethanol for $2 \mathrm{~min}$. They were separately rinsed three times with sterile distilled water and placed on a sterile paper towel in a laminar flow cabinet to air dry. After drying six pieces of each treated stem were randomly selected and plated separately onto $B$. bassiana selective medium..$^{27}$ The inoculated plates were incubated for 15 days at $25^{\circ} \mathrm{C}$. The plates were monitored every 2-3 days for the emergence of fungal mycelia. After colonisation of the stems by $B$. bassiana isolates was confirmed, the remaining inoculated plants were harvested, washed with tap water, and the stems were then used for pathogenicity testing on the stem borer, S. calamistis.

\section{Efficacy of $\mathrm{B}$. bassiana isolates against $\mathrm{S}$. calamistis}

The endophyte positive stems produced as previously described were harvested and washed with distilled water, before being fed to the third instar larvae of $S$. calamistis. A total of 10 third instar larvae of $S$. calamistis were placed into plastic containers of $10 \mathrm{~g}$ of $B$. bassiana infected rice stems. The containers were placed in an incubator at $28^{\circ} \mathrm{C}$. Mortality of the larvae was recorded after 7, 14, 21 and 28 days. For the control, larvae were fed with non-inoculated rice stems. Dead larvae were collected at 7, 14, 21 and 28 days and were maintained in plastic containers on Whatman filter paper previously wetted with sterile distilled water. Two to three days after collection, the dead larvae were surface sterilised in $3 \%$ sodium hypochlorite for 1 min followed by $70 \%$ ethanol for $1 \mathrm{~min}$. They were then rinsed three times with sterile distilled water for $15 \mathrm{~s}$. The surface-sterilised dead larvae were placed on sterile paper towels under a laminar flow cabinet for air drying. The dried dead larvae were plated onto Petri dishes that contained a $B$. bassiana selective media ${ }^{27}$ (Figure 2). The plates were kept in an incubator at $26-28^{\circ} \mathrm{C}$ and monitored every 2-3 days. Fungi that appeared on the surface-sterilised larvae of $S$. calamistis were harvested and sub-cultured onto fresh PDA plates for pure culture and identification. After 15 days, the colonies were compared to the endophytic $B$. bassiana isolates that were initially inoculated onto the rice seed. The experiment was performed three times to confirm the pathogenicity of the $B$. bassiana isolates.

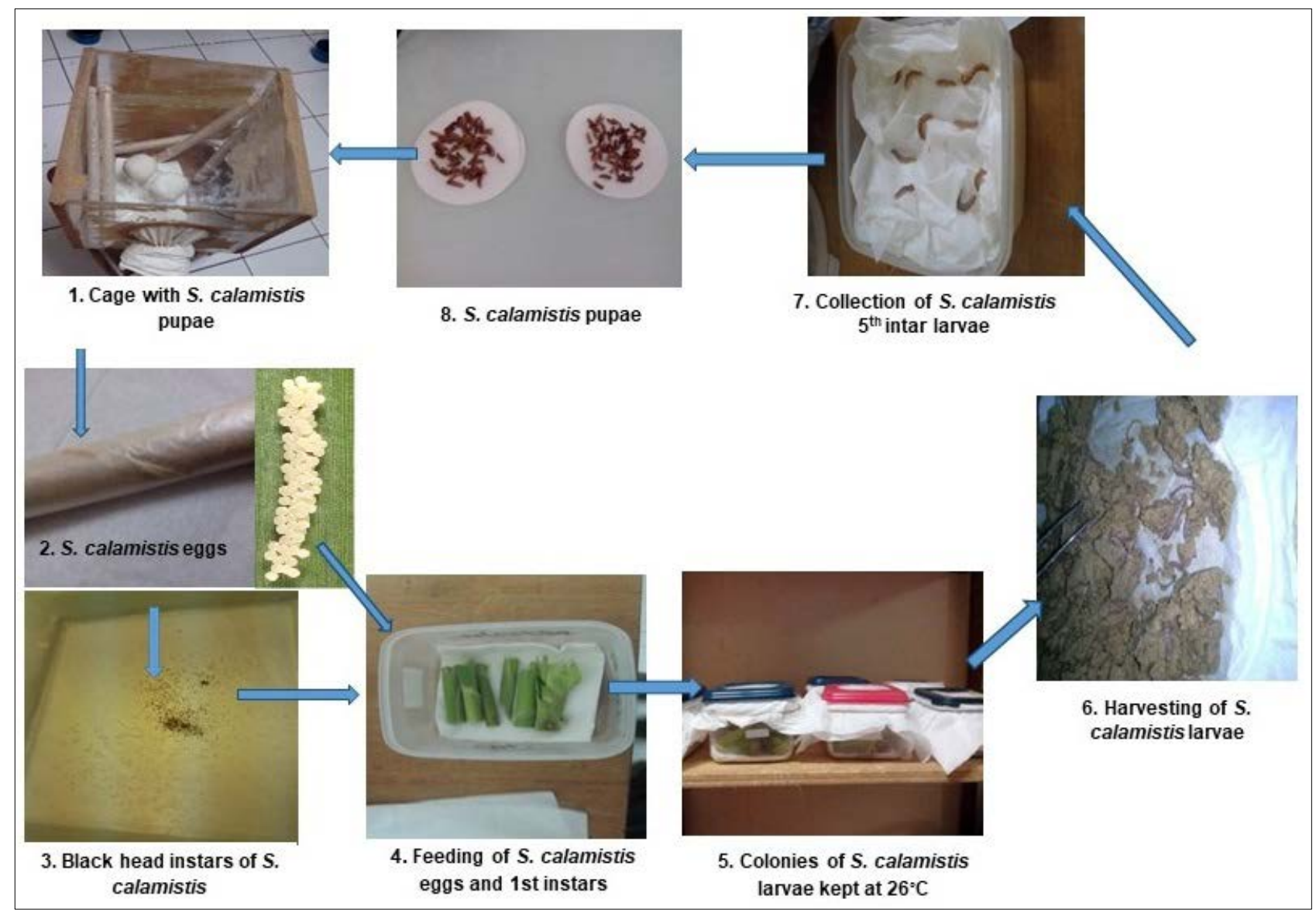

Figure 1: Steps in the artificial rearing of Sesamia calamistis. 


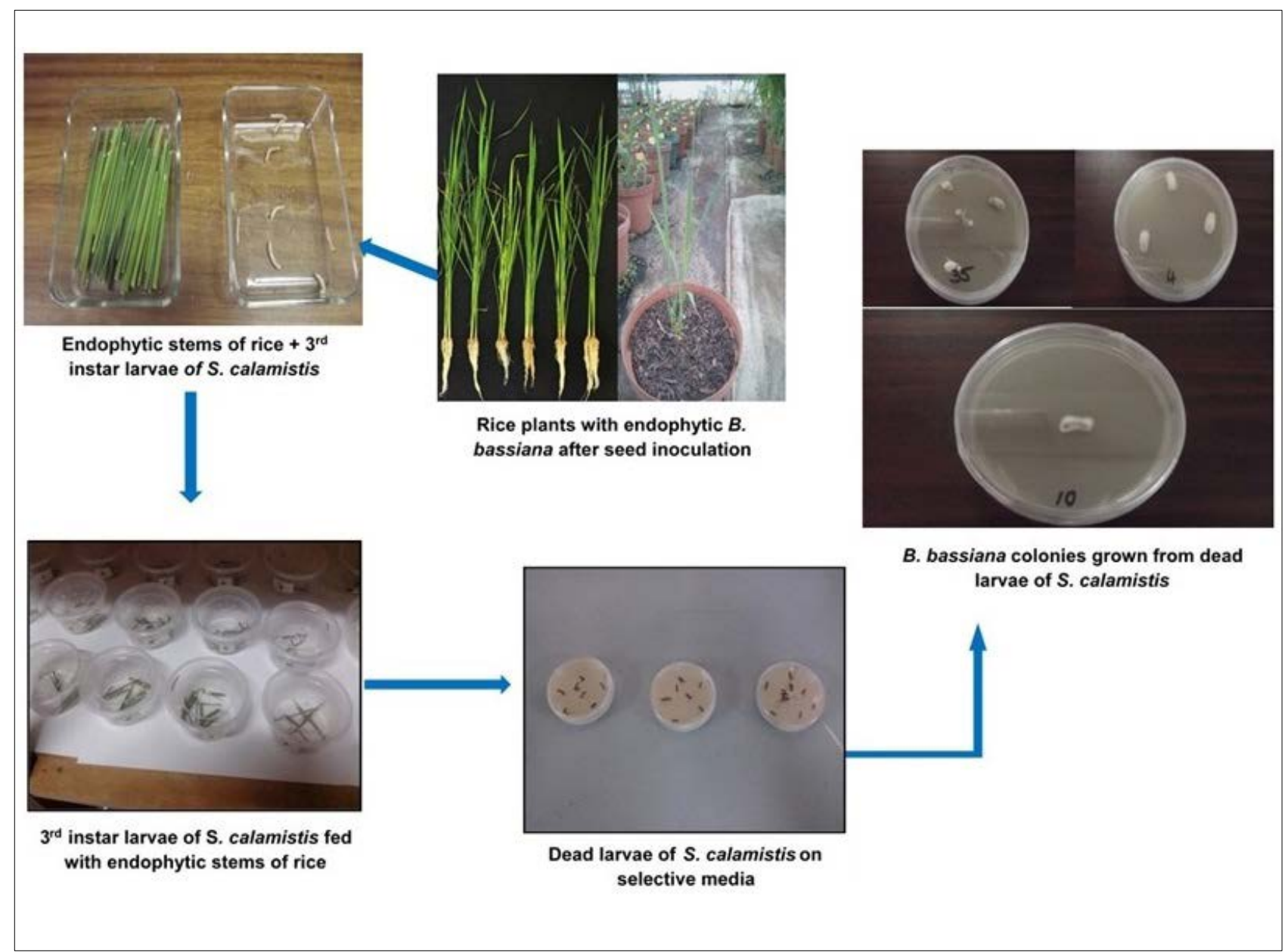

Figure 2: In-vivo screening of endophytic isolates of Beauveria bassiana for pathogenicity activity against third instar larvae of Sesamia calamistis.

\section{Data analysis}

Colonisation of the rice plant tissues resulting from the various treatment combinations was analysed using SAS (version 9.4). A general linear model was used for the analysis of variance (ANOVA). If the ANOVA F-test was significant $(p<0.05)$, then treatment means were separated using the Duncan Multiple Range Test.

The cumulative percentage of mortality of $S$. calamistis was recorded, and the area under the mortality progress curve (AUMPC) was calculated. The data collected were analysed using GenStat (18th edition). A twoway ANOVA was run with $B$. bassiana isolates and time (days) as the main factors.

\section{Results}

The rice plants were colonised by $B$. bassiana isolates using both inoculation methods. The colonisation of each rice plant tissue (root, stem and leaf) was both isolate and inoculation method dependent and varied also with time (30-60 days) (Tables 1 and 2).

Following seed treatment, highly significant differences were observed in the colonisation of the tissues (roots, stem and leaves) $\times B$. bassiana isolates $(p=0.0001)$ and $x$ rice cultivar $(p=0.0001)$. At both 30 and 60 days for all interactions [(isolates $x$ cultivars, isolates $x$ time, cultivars $x$ time and isolates $x$ cultivars $x$ time] there were highly significant differences in the colonisation of the roots and the leaves $(p=0.0001)$. There was no interaction between strain $\mathrm{x}$ time $(p=0.32)$ (Table 1).

After foliar sprays of inoculum, highly significant differences were observed in the levels of colonisation of the roots between $B$. bassiana isolates, rice cultivars, $B$. bassiana isolates $\mathrm{x}$ cultivars, $B$. bassiana isolates $\mathrm{x}$ time, cultivars $\mathrm{x}$ time, and $B$. bassiana isolates $\mathrm{x}$ cultivars $x$ time $(p=0.0001$; Table 2). Highly significant differences were observed in colonisation of the leaves between $B$. bassiana isolates, cultivars, time (30-60 days), $B$. bassiana isolates $x$ cultivars, $B$. bassiana isolates $\mathrm{x}$ time, cultivars $\mathrm{x}$ time, and $B$. bassiana isolates $\mathrm{x}$ cultivars $\mathrm{x}$ time $(p=0.0001)$. In the stem, significant differences were observed between strains $(p=0.005)$, time $(p=0.02)$ and cultivars $x$ time $(p=0.0018)$. The interactions of $B$. bassiana isolates $\mathrm{x}$ cultivars, and $B$. bassiana isolates $\mathrm{x}$ cultivars $\mathrm{x}$ time were highly significant $(p=0.0001$ and $p=0.0002$, respectively). No colonisation by $B$. bassiana isolates was observed in the tissues of the control plants, with either inoculation method (Tables 1 and 2).

There were highly significant differences between the pathogenicity of the five $B$. bassiana isolates that were used against the third instar larvae of $S$. calamistis ( $p=0.001$; Table 3 ). B. bassiana isolates $\mathrm{Bb} 4$ and $\mathrm{Bb} 35$ were the most effective strains, killing $93.3 \%$ and $76.6 \%$ of $S$. calamistis larvae at 28 days, respectively (Figure 3 ). The AUMPC data revealed that the $B$. bassiana isolates $\mathrm{Bb} 4$ vs $\mathrm{Bb} 35, \mathrm{Bb} 35$ vs $\mathrm{Bb} 10$ and $\mathrm{Bb} 10$ vs $\mathrm{Bb} 3$ showed similar levels of pathogenicity (Table 3 ). 
Table 1: Evaluation of endophytic behaviour of Beauveria bassiana strains in rice plants following seed inoculation

\begin{tabular}{|c|c|c|c|c|c|c|c|c|}
\hline B. bassiana isolate & Rice cultivar & Time (days) & \multicolumn{2}{|c|}{ No. of root sections colonised } & \multicolumn{2}{|c|}{ No. of stem sections colonised } & \multicolumn{2}{|c|}{ No. of leaf sections colonised } \\
\hline Bb3 & NERICA1 & 30 & \multicolumn{2}{|c|}{$6.0 \mathrm{a}$} & \multicolumn{2}{|c|}{$6.0 \mathrm{a}$} & \multicolumn{2}{|c|}{$4 \mathrm{~b}$} \\
\hline Bb3 & NERICA8 & 30 & \multicolumn{2}{|c|}{$6.0 \mathrm{a}$} & \multicolumn{2}{|c|}{$6.0 \mathrm{a}$} & \multicolumn{2}{|c|}{$2 c$} \\
\hline Bb3 & NERICA.L.19 & 30 & \multicolumn{2}{|c|}{$3.33 \mathrm{c}$} & \multicolumn{2}{|c|}{$2 \mathrm{c}$} & \multicolumn{2}{|c|}{$0 \mathrm{e}$} \\
\hline $\mathrm{Bb} 4$ & NERICA1 & 30 & \multicolumn{2}{|c|}{$4 \mathrm{~b}$} & \multicolumn{2}{|c|}{$4 \mathrm{~b}$} & \multicolumn{2}{|c|}{$2 \mathrm{c}$} \\
\hline Bb4 & NERICA8 & 30 & \multicolumn{2}{|c|}{$6.0 \mathrm{a}$} & \multicolumn{2}{|c|}{$4 \mathrm{~b}$} & \multicolumn{2}{|c|}{$4 \mathrm{~b}$} \\
\hline Bb4 & NERICA.L.19 & 30 & \multicolumn{2}{|c|}{$4 \mathrm{~b}$} & \multicolumn{2}{|c|}{$4 \mathrm{~b}$} & \multicolumn{2}{|c|}{$2 c$} \\
\hline Bb10 & NERICA1 & 30 & \multicolumn{2}{|c|}{$6.0 \mathrm{a}$} & \multicolumn{2}{|c|}{$6.0 \mathrm{a}$} & & \\
\hline $\mathrm{Bb} 10$ & NERICA8 & 30 & & & & & & \\
\hline Bb10 & NERICA.L.19 & 30 & & & & & & \\
\hline Bb21 & NERICA1 & 30 & & & & & & \\
\hline Bb21 & NERICA8 & 30 & & & & & & \\
\hline Bb21 & NERICA.L.19 & 30 & & & & & & \\
\hline Bb35 & NERICA1 & 30 & & & & & & \\
\hline Bb35 & NERICA8 & 30 & & & & & & \\
\hline Bb35 & NERICA.L.19 & 30 & & & & & & \\
\hline Bb3 & NERICA1 & 60 & & & & & & \\
\hline Bb3 & NERICA8 & 60 & & & & & & \\
\hline Bb3 & NERICA.L.19 & 60 & & & & & & \\
\hline Bb4 & NERICA1 & 60 & & & & & & \\
\hline $\mathrm{Bb} 4$ & NERICA8 & 60 & & & & & & \\
\hline Bb4 & NERICA.L.19 & 60 & & & & & & \\
\hline Bb10 & NERICA1 & 60 & & & & & & \\
\hline $\mathrm{Bb} 10$ & NERICA8 & 60 & & & & & & \\
\hline $\mathrm{Bb} 10$ & NERICA.L.19 & 60 & & & & & & \\
\hline Bb21 & NERICA1 & 60 & & & & & & \\
\hline Bb21 & NERICA8 & 60 & & & & & & \\
\hline Bb21 & NERICA.L.19 & 60 & & & & & & \\
\hline Bb35 & NERICA1 & 60 & & & & & & \\
\hline Bb35 & NERICA8 & 60 & & & & & & \\
\hline Bb35 & NERICA.L.19 & 60 & & & & & & \\
\hline Control 1 & NERICA1 & 60 & & & & & & \\
\hline Control 2 & NERICA8 & 60 & & & & & & \\
\hline Control 3 & NERICA.L.19 & 60 & & & & & & \\
\hline & Effect & & F-value & $p$-value & F-value & $p$-value & F-value & $p$-value \\
\hline Isolates & & & 176.91 & $0.0001^{* * *}$ & 3.87 & $0.0054^{\star *}$ & 310.23 & $0.0001^{* \star *}$ \\
\hline Cultivars & & & 1050.54 & $0.0001^{* \star *}$ & 9.95 & $0.0001^{* *}$ & 2225.67 & $0.0001^{\star \star \star}$ \\
\hline Time & & & 1 & $0.3213 \mathrm{NS}$ & 5.26 & $0.0235^{\star}$ & 1444.96 & $0.0001 * \star \star$ \\
\hline Isolate x cultivar & & & 245.02 & $0.0001^{* * *}$ & 9.55 & $0.0001^{* * *}$ & 1129.84 & $0.0001^{\star \star \star *}$ \\
\hline Isolate $x$ time & & & 89.16 & $0.0001^{* * *}$ & 1.18 & $0.3213 \mathrm{NS}$ & 634.5 & $0.0001 * * *$ \\
\hline Cultivar x time & & & 493.85 & $0.0001^{\star \star \star}$ & 6.68 & $0.0018^{\star \star}$ & 1264.83 & $0.0001^{\star \star \star}$ \\
\hline Isolate $x$ cultivar $x$ time & & & 252.87 & $0.0001^{* * *}$ & 4.18 & $0.0002^{\star *}$ & 1039.79 & $0.0001^{* * *}$ \\
\hline & $\%$ CV & & & & & & & \\
\hline
\end{tabular}

Means with the same letter are not significantly different $(\mathrm{p}=0.05)$ according to the Duncan Multiple Range Test.

***Highly significant; **and *significant; NS, not significant; $B b$, B. bassiana isolate 
Table 2: Evaluation of endophytic behaviour of Beauveria bassiana strains in rice plants using foliar sprays inoculation

\begin{tabular}{|c|c|c|c|c|c|c|c|c|}
\hline B. bassiana isolate & Rice cultivar & Time (days) & \multicolumn{2}{|c|}{ No. of root sections colonised } & \multicolumn{2}{|c|}{ No. of stem sections colonised } & \multicolumn{2}{|c|}{ No. of leaf sections colonised } \\
\hline Bb3 & NERICA1 & 30 & \multicolumn{2}{|c|}{$0 \mathrm{~g}$} & \multicolumn{2}{|c|}{$6.0 \mathrm{a}$} & \multicolumn{2}{|c|}{$6.0 \mathrm{a}$} \\
\hline Bb3 & NERICA8 & 30 & \multicolumn{2}{|c|}{$6.0 \mathrm{a}$} & \multicolumn{2}{|c|}{$6.0 \mathrm{a}$} & \multicolumn{2}{|c|}{$6.0 \mathrm{a}$} \\
\hline Bb3 & NERICA.L.19 & 30 & \multicolumn{2}{|c|}{$2 f$} & \multicolumn{2}{|c|}{$2 c$} & \multicolumn{2}{|c|}{$6.0 \mathrm{a}$} \\
\hline $\mathrm{Bb} 4$ & NERICA1 & 30 & \multicolumn{2}{|c|}{$0 \mathrm{~g}$} & \multicolumn{2}{|c|}{$0 d$} & \multicolumn{2}{|c|}{$2 c$} \\
\hline Bb4 & NERICA8 & 30 & \multicolumn{2}{|c|}{$0 \mathrm{~g}$} & \multicolumn{2}{|c|}{$4 \mathrm{~b}$} & \multicolumn{2}{|c|}{$4 \mathrm{~b}$} \\
\hline $\mathrm{Bb} 4$ & NERICA.L.19 & 30 & \multicolumn{2}{|c|}{$4 \mathrm{dc}$} & \multicolumn{2}{|c|}{$4 \mathrm{~b}$} & \multicolumn{2}{|c|}{$6.0 \mathrm{a}$} \\
\hline Bb10 & NERICA1 & 30 & \multicolumn{2}{|c|}{$4 \mathrm{dc}$} & \multicolumn{2}{|c|}{$4 \mathrm{~b}$} & & \\
\hline Bb10 & NERICA8 & 30 & & & & & & \\
\hline Bb10 & NERICA.L.19 & 30 & & & & & & \\
\hline $\mathrm{Bb} 21$ & NERICA1 & 30 & & & & & & \\
\hline $\mathrm{Bb} 21$ & NERICA8 & 30 & & & & & & \\
\hline $\mathrm{Bb} 21$ & NERICA.L.19 & 30 & & & & & & \\
\hline Bb35 & NERICA1 & 30 & & & & & & \\
\hline Bb35 & NERICA8 & 30 & & & & & & \\
\hline Bb35 & NERICA.L.19 & 30 & & & & & & \\
\hline Bb3 & NERICA1 & 60 & & & & & & \\
\hline Bb3 & NERICA8 & 60 & & & & & & \\
\hline Bb3 & NERICA.L.19 & 60 & & & & & & \\
\hline Bb4 & NERICA1 & 60 & & & & & & \\
\hline $\mathrm{Bb} 4$ & NERICA8 & 60 & & & & & & \\
\hline $\mathrm{Bb} 4$ & NERICA.L.19 & 60 & & & & & & \\
\hline Bb10 & NERICA1 & 60 & & & & & & \\
\hline Bb10 & NERICA8 & 60 & & & & & & \\
\hline Bb10 & NERICA.L.19 & 60 & & & & & & \\
\hline $\mathrm{Bb} 21$ & NERICA1 & 60 & & & & & & \\
\hline $\mathrm{Bb} 21$ & NERICA8 & 60 & & & & & & \\
\hline $\mathrm{Bb} 21$ & NERICA.L.19 & 60 & & & & & & \\
\hline Bb35 & NERICA1 & 60 & & & & & & \\
\hline Bb35 & NERICA8 & 60 & & & & & & \\
\hline Bb35 & NERICA.L.19 & 60 & & & & & & \\
\hline Control 1 & NERICA1 & 60 & & & & & & \\
\hline Control 2 & NERICA8 & 60 & & & & & & \\
\hline Control 3 & NERICA.L.19 & 60 & & & & & & \\
\hline & Effect & & F-value & $p$-value & F-value & $p$-value & F-value & $p$-value \\
\hline Isolates & & & 209 & $0.0001^{\star \star \star}$ & 3.87 & $0.0054^{\star *}$ & 3302.81 & $0.0001^{\star * *}$ \\
\hline Cultivars & & & 232.79 & $0.0001^{* \star *}$ & 9.95 & $0.0001^{\star *}$ & 1683.04 & $0.0001^{* * *}$ \\
\hline Time & & & 600.4 & $0.3213 \mathrm{NS}$ & 5.26 & $0.0235^{\star}$ & 16.01 & $0.0002^{\star *}$ \\
\hline Isolate $\mathrm{x}$ cultivar & & & 572.81 & $0.0001 * * *$ & 9.55 & $0.0001^{* * *}$ & 1998.31 & $0.0001^{* * *}$ \\
\hline Isolate $\mathrm{x}$ time & & & 336.57 & $0.0001 * * *$ & 1.18 & 0.3213 NS & 495.88 & $0.0001^{* * *}$ \\
\hline Cultivar $\mathrm{x}$ time & & & 232.83 & $0.0001^{* * *}$ & 6.68 & $0.0018^{\star \star}$ & 555.78 & $0.0001^{* \star *}$ \\
\hline Isolate $\mathrm{x}$ cultivar $\mathrm{x}$ time & & & 205.28 & $0.0001^{* * *}$ & 4.18 & $0.0002^{\star \star}$ & 270.94 & $0.0001^{* * *}$ \\
\hline & $\%$ CV & & & & & & & \\
\hline
\end{tabular}

Means with the same letter are not significantly different at $\mathrm{p}=0.05$ according to the Duncan Multiple Range Test.

***Highly significant; **and *significant; NS, not significant; $B b$, B. bassiana isolate 
Table 3: Evaluation of the pathogenicity of five Beauveria bassiana strains against Sesamia calamistis

\begin{tabular}{|c|c|c|}
\hline B. bassiana isolate & \multicolumn{2}{|c|}{ AUMPC mean after 28 days } \\
\hline Bb3 & \multicolumn{2}{|c|}{$1540 \mathrm{c}$} \\
\hline Bb4 & \multicolumn{2}{|c|}{$793 \mathrm{a}$} \\
\hline Bb10 & \multicolumn{2}{|c|}{1225 bc } \\
\hline Bb21 & \multicolumn{2}{|c|}{$2007 d$} \\
\hline Bb35 & \multicolumn{2}{|c|}{$1108 a b$} \\
\hline Effect & $p$-value & Significance \\
\hline Isolates & 0.001 & $\star *$ \\
\hline Bb4 vs Bb35 & 0.06 & NS \\
\hline $\mathrm{Bb} 4$ vs Bb10 & 0.02 & $\star \star$ \\
\hline Bb4 vs Bb3 & 0.0005 & $\star \star \star$ \\
\hline $\mathrm{Bb} 4$ vs Bb21 & 0.0001 & $\star \star \star$ \\
\hline Bb35 vs Bb10 & 0.45 & NS \\
\hline Bb35 vs Bb3 & 0.02 & $\star \star$ \\
\hline $\mathrm{Bb} 35$ vs Bb21 & 0.0001 & $\star \star \star$ \\
\hline $\mathrm{Bb} 10$ vs Bb3 & 0.06 & NS \\
\hline $\mathrm{Bb} 10$ vs Bb21 & 0.0004 & $\star * *$ \\
\hline Bb3 vs Bb21 & 0.01 & $\star \star$ \\
\hline$\%$ CV & 13.6 & \\
\hline
\end{tabular}

Means with the same letter are not significantly different $(\mathrm{p}=0.05)$.

AUMPC, area under the mortality progress curve

***Highly significant; ** significant; NS, not significant

\section{Discussion}

Beauveria bassiana has been reported to colonise many plants as an endophyte ${ }^{24-30}$, which supports the results of our study. Colonisation of plants by $B$. bassiana depends on the inoculation method, fungal isolate and plant species. Some isolates of $B$. bassiana were able to colonise maize plants via the epidermis, thereafter persisting in the plant throughout the entire growing season, and reducing tunnelling by Ostrinia nubilalis Hubner (Lepidoptera: Pyralidae). ${ }^{31,32}$ As demonstrated in this study, $B$. bassiana can become established as an endophyte in rice when seeds or seedlings are inoculated with conidia of $B$. bassiana strains. Similar results have been demonstrated in other studies. ${ }^{25,33,34}$ Successful $B$. bassiana colonisation of coffee leaves ${ }^{21}$, banana roots ${ }^{35}$ and maize plants ${ }^{29}$ has been reported. These studies used inoculation techniques such as leaf injection, seed treatment, root drench and foliar sprays. All these techniques led to successful $B$. bassiana inoculation and colonisation.

The level of colonisation of the various plant tissues (leaf, root and stem) differed according to the $B$. bassiana isolates and the rice cultivars used in this study. The inoculation methods used conferred good colonisation of the rice stem by some of the $B$. bassiana isolates. Our study confirmed that there are several possible pathways to inoculation and recovery of $B$. bassiana from plant tissues. ${ }^{36}$ Both inoculation methods (seed treatment and foliar spray) resulted in high levels of leaf and root colonisation. The inoculation method did not appear to favour a specific pattern of local colonisation of the rice cultivars. This is contrary to the results of Posada et al. ${ }^{21}$ who reported that foliar sprays favoured leaf colonisation, whereas soil drenching favoured root colonisation in coffee. Similar findings were demonstrated for the common bean. ${ }^{25}$

The systemic spread of each $B$. bassiana isolate differed over the two sampling time periods (30 and 60 days) used in this study. A reduction in level of colonisation over time may have been caused by a host resistance response to the heterotrophic fungi or because of competition from other endophytes in the rice tissues. ${ }^{23}$ The colonisation of the rice cultivars by the $B$. bassiana isolates did not cause any apparent negative effects on the growth of the rice plants, as was reported by Van Bael et al. ${ }^{37}$

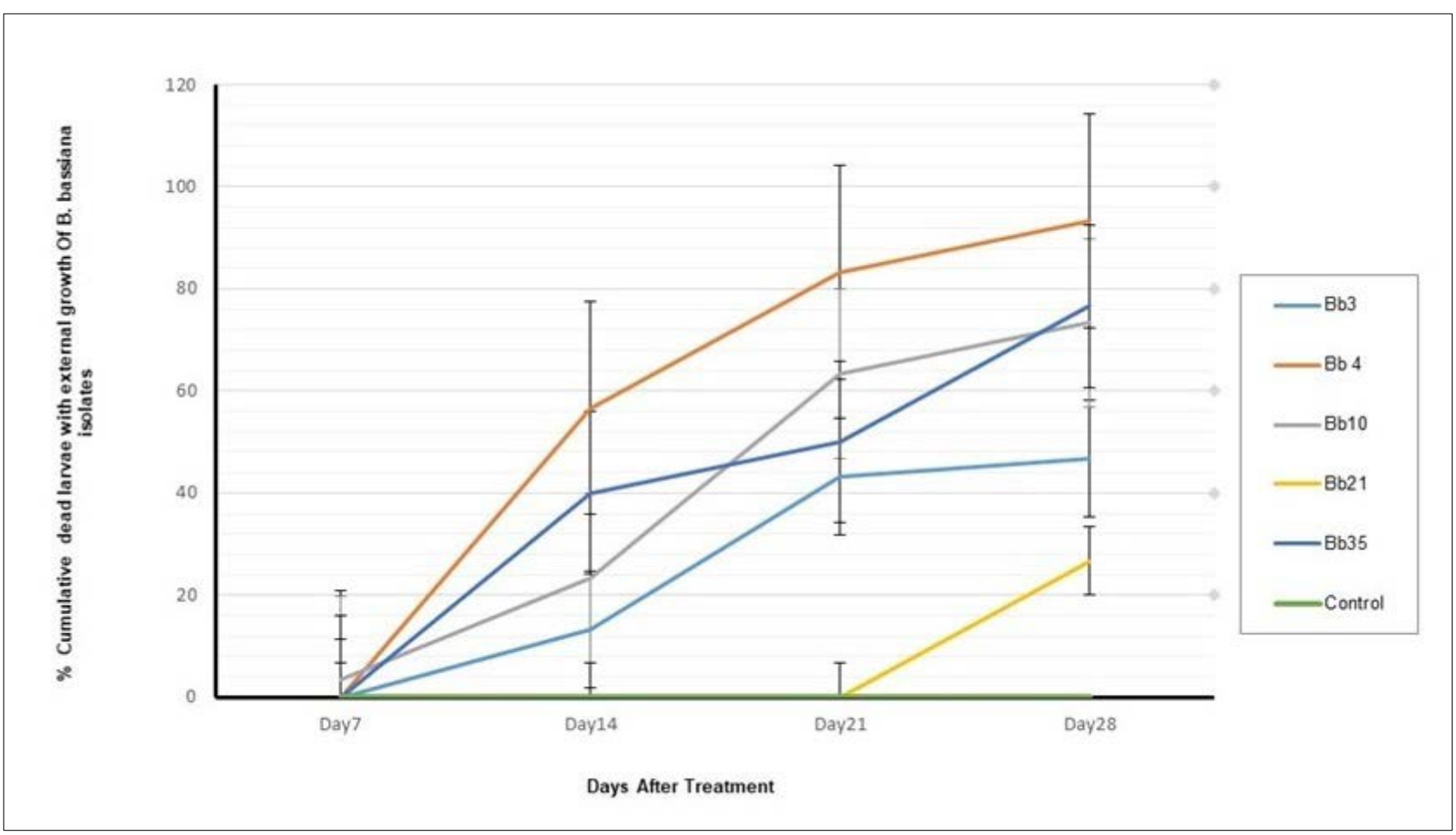

Figure 3: Cumulative mortality (\%) of third instar larvae of Sesamia calamistis caused by five endophytic Beauveria bassiana isolates. 
Gurulingappa et al ${ }^{38}$ reported that fungal isolates from different insect hosts possess varying degrees of virulence to the different insects. In this study, the five $B$. bassiana isolates showed differential pathogenicity against the third instar larvae of S. calamistis. Mortalities of $93.3 \%$ and $76.6 \%$ were achieved on third instar larvae of $S$. calamistis with two of the five selected $B$. bassiana strains used in this study. Similarly, a lower frequency of $S$. calamistis was recorded in $B$. bassiana treated maize plants compared to non-inoculated maize plants. ${ }^{39}$

Research from Valda et al. ${ }^{40}$ and Godonou et al. ${ }^{41}$ proved the effectiveness of $B$. bassiana strains on a diamondback moth population, Plutella xylostella L. (Lepidoptera: Plutellidae). Similarly, the survivorship and development of banana weevil larvae, Cosmopolites sordidus Germar (Coleoptera: Curculionidae) were significantly affected by endophytic B. bassiana strain $\mathrm{s}^{35}$ as were the adult banana weevils as reported in Ghana. ${ }^{41}$ Tesfaye et al. ${ }^{42}$ also isolated different strains of $B$. bassiana and found that they caused mortalities greater than $75 \%$ of adults of Myzus persicae Sulzer (Homoptera: Aphididae). Bing and Lewis ${ }^{31,32}$ found that $60 \%$ of 0 . nubilalis larvae collected from maize plants inoculated with $B$. bassiana were controlled by the fungus. A reduction in feeding is one of the reported altered behaviours by insects when infected by $B$. bassiana. For example, Tefera and Pringle ${ }^{26}$ showed that there was a significant reduction in feeding by Chilo partellus Swinhoe (Lepidoptera: Pyralidae) as a result of 1-4 days inoculation with $B$. bassiana. The results reported in this study differ from that previously reported by Cherry et al. ${ }^{39}$ The difference in the results may be due to the different strains of $B$. bassiana and inoculation methods used in the two studies. The results from this study therefore indicate that two of the five $B$. bassiana isolates used in this study have potential as biological control agents against $S$. calamistis in rice.

\section{Conclusion}

This study revealed that rice cultivars could be colonised by strains of $B$. bassiana. The five $B$. bassiana isolates tested in this study were endophytic with various degrees of colonisation and pathogenicity against the rice stem borer, $S$. calamistis. The results of this study indicate that two of the five tested $B$. bassiana isolates hold promise as biological control agents of rice stem borers. Further studies under field conditions at different sites and seasons are needed to ascertain the potential of these isolates. From this study, seed treatment seems to be the most appropriate and practical way to introduce the best $B$. bassiana strains during field studies. The field experiments will be implemented where rice is grown on a large scale using an experimental formulation of the best two $B$. bassiana strains.

\section{Acknowledgements}

This study was funded by the Organization for Women in Science for the Developing World (OWSD) and Plant Health Products (KwaZulu-Natal, South Africa).

\section{Competing interests}

We declare that there are no competing interests.

\section{Authors' contributions}

W.B.A.B. wrote the initial manuscript, collected the samples, isolated the endophytic fungus, and performed all the morphological, in vitro and in vivo bioassays. A.T. provided guidance and the protocol for the rearing of the borer, Sesamia calamistis. M.D.L. and K.S.Y. provided student supervision, project leadership and management, acquired the funding, and edited the manuscript.

\section{References}

1. Chapagain A, Hoekstra A. The blue, green and grey water footprint of rice from production and consumption perspectives. Ecol Econ. 2011;70:749 758. https:/doi.org/10.1016/j.ecolecon.2010.11.012

2. Kfir R. Attempts at biological control of the stem borer Chilo partellus Swinhoe (Lepidoptera: Pyralidae) in South Africa. Afr Entomol. 1994;2:67-68.

3. Van Nguyen N, Ferrero A. Meeting the challenges of global rice production. Paddy Water Environ. 2006;4:1-9. https://doi.org/10.1007/s10333-005-0031-5
4. Khush GS. What it will take to feed 5.0 billion rice consumers in 2030. Plant Mol Biol. 2005;59:1-6. https://doi.org/10.1007/s11103-005-2159-5

5. AfricaRice Center. Boosting Africa's rice sector: A research for development strategy 2011-2020. Cotonou, Benin: AfricaRice; 2011

6. Bardenas EA, Chang TT. Morphology and varietal characteristics of the rice plant Los Banos, the Philippines: The International Rice Research Institute; 1965.

7. Bing LA, Lewis LC. Occurrence of the entomopathogen Beauveria bassiana (Balsamo) Vuillemin in different tillage regimes and in Zea mays $L$. and virulence towards Ostrinia nubilalis (Hubner). Agr Ecosyst Environ. 1993;45:147-156. https://doi.org/10.1016/0167-8809(93)90065-W

8. Seck PA, Tollens E, Wopereis MC, Diagne A, Bamba I. Rising trends and variability of rice prices: Threats and opportunities for sub-Saharan Africa. Food Policy. 2010;35:403-411. https://doi.org/10.1016/j.foodpol.2010.05.003

9. Somado E, Guei R, Keya S. NERICA: The New Rice for Africa, a compendium. Cotonou, Benin: Africa Rice Center (WARDA); 2008.

10. Quesada-MoragaE, Munoz-LedesmaF, Santiago-Alvarez C. Systemic protection of Papaver somniferum L. against Iraella luteipes (Hymenoptera: Cynipidae) by an endophytic strain of Beauveria bassiana (Ascomycota: Hypocreales) Environ Entomol. 2009;38:723730. https://doi.org/10.1603/022.038.0324

11. Van den Berg J, Van Rensburg J. Comparison of various directional insecticide sprays against Busseola fusca Fuller (Lepidoptera: Noctuidae) and Chilo partellus Swinhoe (Lepidoptera: Pyralidae) in sorghum and maize. S Afr J Plant Soil. 1996;13:51-54. https://doi.org/10.1080/02571862.1996.10634375

12. Warui $\mathrm{C}$, Kuria J. Population incidence and the control of maize stalk borers Chilo partellus Swinhoe, C. orichalcociliellus Strand and Sesamia calamistis Hampson, in Coast Province, Kenya. Int J Trop Ins Sci. 1983;4:11-18. https:// doi.org/10.1017/S1742758400003970

13. Ignoffo CM, Puttler B, Hostetter DL, Dickerson WA. Susceptibility of the cabbage looper, Trichoplusia ni, and the velvet bean caterpillar, Anticarsia gemmatalis, to several isolates of the entomopathogenic fungus Nomuraearileyi. J Invertebr Pathol. 1976;28:259-262. https://doi.org/10.1016/0022-2011(76)90132-4

14. Deedat YD. Problems associated with the use of pesticides: An overview. Int $J$ Trop Ins Sci. 1994;15:247-251. https://doi.org/10.1017/S1742758400017537

15. Godonou I, Green KR, Oduro KA, Lomer CJ, Afreh-Nuamah K. Field evaluation of selected formulations of Beauveria bassiana for the management of the banana weevil (Cosmopolites sordidus) on plantain (Musa spp. AAB Group). Biocontrol Sci Technol. 2000;10:779-788. https://doi.org/10.1080/09583150020011726

16. Kfir R. Seasonal abundance of the stem borer Chilo partellus Swinhoe (Lepidoptera: Pyralidae) and its parasites on summer grain crops. J Econ Entomol. 1992;85:518-529. https://doi.org/10.1093/jee/85.2.518

17. Pathak MD, Khan ZR. Insect pests of rice. Los Banos, Philippines: International Rice Research Institute; 1994.

18. Parsa S, Ortiz V, Vega FE. Establishing fungal entomopathogens as endophytes: towards endophytic biological control. J Vis Exp. 2013;74, e50360. https://doi org/10.3791/50360

19. Cherry AJ, Lomer CJ, Djegui D, Schulthess F. Pathogen incidence and their potential as microbial control agents in IPM of maize stem borers in West Africa. BioControl. 1999;44:301-327. https://doi.org/10.1023/A:1009991724251

20. Kikuchi M, Haneishi Y, Tokida K, Maruyama A, Godfrey A, Tsuboi T. The structure of rice retail markets in sub-Saharan Africa. Trop Agric Development 2015;59:127-139. https://doi.org/10.11248/jsta.59.127

21. Posada F, Aime MC, Peterson SW, Rehner SA, Vega FE. Inoculation of coffee plants with the fungal entomopathogen Beauveria bassiana (Ascomycota: Hypocreales). Mycol Res. 2007;111:748-757. https://doi.org/10.1016/j. mycres.2007.03.006

22. Akello J, Dubois T, Gold CS, Coyne D, Nakavuma J, Paparu P. Beauveria bassiana (Balsamo) Vuillemin as an endophyte in tissue culture banana (Musa spp). J Invertebr Pathol. 2007;96:34-42. https://doi.org/10.1016/j.jip.2007.02.004

23. PimentelD, Acquay H, Biltonen M, Rice P, Silva M, Nelson J, et al. Environmental and economic costs of pesticide use. Bioscience. 1992;42:750-760. https:// doi.org/10.2307/1311994

24. Wagner BL, Lewis LC. Colonization of corn, Zea mays, by the entomopathogenic fungus, Beauveria bassiana. Appl Environ Microbiol. 2000;66:3468-3473. https://doi.org/10.1128/AEM.66.8.3468-3473.2000 
25. Ownley BH, Griffin MR, Klingeman WE, Gwinn KD, Moulton JK, Pereira RM. Beauveria bassiana: Endophytic colonization and plant disease control. J Invertebr Pathol. 2008;98:267-270. https://doi.org/10.1016/j.jip.2008.01.010

26. Tefera T, Pringle K. Food consumption by Chilo partellus (Lepidoptera: Pyralidae) larvae infected with Beauveria bassiana and Metarhizium anisopliae and effects of feeding natural versus artificial diets on mortality and mycosis. J Invertebr Pathol. 2003;84:220-225. https://doi.org/10.1016/j.jip.2003.11.001

27. Dobeski JW, Tribe HT. Isolation of entomogenous fungi from elm bark and soil with reference to ecology of Beauveria bassiana and Metarhizium anisopliae. Trans Br Mycol Soc. 1980;74:95-100. https://doi.org/10.1016/S00071536(80)80013-1

28. Qazi SS, Khachatourians GG. Insect pests of Pakistan and their management practices: Prospects for the use of entomopathogenic fungi. Biopest Int. 2005;1:13-24.

29. Tefera T, Vidal S. Effect of inoculation method and plant growth medium on endophytic colonization of sorghum by the entomopathogenic fungus Beauveria bassiana. BioControl. 2009;54:663-669. https://doi.org/10.1007/ s10526-009-9216-y

30. Vega FE, Posada F, Aime MC, Pava-Ripoll M, Infante F, Rehner SA. Entomopathogenic fungal endophytes. Biol Control. 2008; 46:72-82. https:// doi.org/10.1016/j.biocontrol.2008.01.008

31. Bing LA, Lewis LC. Suppression of Ostrinia nubilalis Hubner (Lepidoptera: Pyralidae) by endophytic Beauveria bassiana (Balsamo) Vuillemin. Environ Entomol. 1991; 20:1207-1211. https://doi.org/10.1093/ee/20.4.1207

32. Bing LA, Lewis LC. Occurrence of the entomopathogen Beauveria bassiana (Balsamo) Vuillemin in different tillage regimes and in Zea mays $\mathrm{L}$. and virulence towards Ostrinia nubilalis (Hubner). Agric Ecosyst Environ. 1993;45:147-156 https://doi.org/10.1016/0167-8809(93)90065-W

33. Akello J, Dubois T, Coyne D, Hillnhutter C. Beauveria bassiana as an endophyte in tissue cultured banana plants: A novel way to combat the banana weevil, Cosmopolites sordidus. III International Symposium on banana: ISHS-ProMusa Symposium on recent advances in banana. Acta Hortic. 2009;828:129-138. https://doi.org/10.17660/ActaHortic.2009.828.12
34. Maniania NK. Pathogenicity of entomogenous fungus (Hyphomycetes) to larvae of the stem borers, Chilo partellus Swinhoe and Busseola fusca Fuller. Int J Trop Insect Sci. 1992;13:691-696. https://doi.org/10.1017/S1742758400007918

35. Akello J, Dubois T, Coyne D, Kyamanywa S. Endophytic Beauveria bassiana in banana (Musa spp) reduces banana weevil (Cosmopolites sordidus) fitness and damage. Crop Prot. 2008;27:1437-1441. https://doi.org/10.1016/j. cropro.2008.07.003

36. Goulson D. Review: An overview of the environmental risks posed by neonicotinoid insecticides. J Appl Ecol. 2013;50:977-987.

37. Van Bael SA, Maynard Z, Rojas E, Mejia LC, Kyloo DA, Herre EA, et al. Emerging perspectives on the ecological roles of endophytic fungi in tropical plants. Mycol Series. 2005;23:181.

38. Gurulingappa P, Sword GA, Murdoch G, McGee PA. Colonization of crop plants by fungal entomopathogens and their effects on two insect pests when in planta. Biol Control. 2010;55:34-41. https://doi.org/10.1016/j. biocontrol.2010.06.011

39. Cherry AJ, Banito A, Djegui D, Lomer C. Suppression of the stem borer Sesamia calamistis (Lepidoptera: Noctuidae) in maize following seed dressing, topical application and stem injection with African isolates of Beauveria bassiana. Int J Pest Manage. 2004;50:67-73. https://doi.org/10 $1080 / 09670870310001637426$

40. Valda CAS, Reginaldo B, Edmilson JM, Jorge BT. Susceptibility of Plutella xylostella (L.) (Lepidoptera: Plutellidae) to the Fungi Beauveria bassiana (Bals.) Vuill. and Metarhizium anisopliae (Metsch.) Sorok Neotrop Entomol 2003;32:653-658. https://doi.org/10.1590/S1519-566X2003000400016

41. Godonou I, James B, Atcha-Ahowe C, Vodouhe S, Kooyman C, Ahanchede $A$, et al. Potential of Beauveria bassiana and Metarhizium anisopliae isolates from Benin to control Plutella xylostella L. (Lepidoptera: Plutellidae). Crop Prot. 2009;28:220-224. https://doi.org/10.1016/j.cropro.2008.10.009

42. Tesfaye D, SeyoumE. Studies on the pathogenicity of native entomopathogenic fungal isolates on the cotton/melon aphid, Aphis gossypii Glover (Homoptera: Aphididae) under different temperature regimes. Afr Entomol. 2010;18:302312. https://doi.org/10.4001/003.018.0215 